[2] Kawalec P, et al. Expert Rev Pharmacoecon Outcomes Res 2015 Feb;15 (1):125-132

[3] 3. Woolacott N, et al. Health Technol Assess 2006 Sep;10(31):iii-iv, xiii-xvi, $1-239$.

[4] Dias SWN, et al. Nice DSU technical support document 2: A generalised linear modelling framework for pairwise and network meta-analysis of randomised controlled trials 2011.

Disclosure of Interest: A. Ruyssen-Witrand: None declared, C. Sapin Employee of: Eli Lilly and Company, S. Hartz Employee of: Eli Lilly and Company, S. Liu Leage Employee of: Eli Lilly and Company

DOI: 10.1136/annrheumdis-2018-eular.2343

\section{THU0291 INCIDENCE OF SERIOUS GASTROINTESTINAL EVENTS AND INFLAMMATORY BOWEL DISEASE AMONG TILDRAKIZUMAB-TREATED PATIENTS WITH MODERATE TO SEVERE PLAQUE PSORIASIS: DATA FROM 3 LARGE RANDOMISED CLINICAL TRIALS}

M. Gooderham ${ }^{1}$, B.E. Elewski ${ }^{2}$, D.M. Pariser ${ }^{3}$, H. Sofen ${ }^{4},{ }^{5}$ A.M. Mendelsohn, N. Cichanowitz ${ }^{6}$, Q. Li ${ }^{6}$, C. La Rosa ${ }^{6} .{ }^{1}$ Probity Medical Research and Skin Centre for Dermatology, Waterloo, ON and Peterborough, ON, Canada; ${ }^{2}$ Department of Dermatology, University of Alabama at Birmingham School of Medicine, Birmingham, AL; ${ }^{3}$ Eastern Virginia Medical School and Virginia Clinical Research, Inc., Norfolk, VA; ${ }^{4}$ Department of Medicine (Dermatology) UCLA, Los Angeles, CA ${ }^{5}$ Sun Pharmaceutical Industries, Inc., Princeton, $\mathrm{NJ}$; ${ }^{6}$ Merck and Co., Inc., Kenilworth, NJ, USA

Background: Tildrakizumab, is a high-affinity, humanised, anti-IL-23p19 monoclonal antibody for the treatment of chronic plaque psoriasis.

Objectives: Here, we evaluated gastrointestinal (GI) adverse events (AE) and, specifically, cases of inflammatory bowel disease (IBD; ie, Crohn's disease or ulcerative colitis) in the clinical development program for tildrakizumab.

Methods: Patients with moderate to severe plaque psoriasis were randomised in 3 large, clinical trials: P05495 (phase 2; NCT01225731), reSURFACE 1 (phase 3; NCT01722331), and reSURFACE 2 (phase 3; NCT01729754). ${ }^{12}$ In this analysis, we identified serious GI AEs and new-onset or exacerbation of pre-existing IBD from a pooled dataset of tildrakizumab-treated patients from these 3 studies. Doses of tildrakizumab included $5 \mathrm{mg}, 25 \mathrm{mg}, 100 \mathrm{mg}$, and $200 \mathrm{mg}$ in P05495 and $100 \mathrm{mg}$ and $200 \mathrm{mg}$ in the reSURFACE studies.

Results: In this analysis, we pooled 1911 patients from the 3 trials who received either tildrakizumab 100 or 200 mg. There were no new cases of IBD reported; among 6 patients with a history of IBD randomised to tildrakizumab, none experienced an exacerbation. The numbers (rate per 100 patient-years) of patients with serious GI AEs in the pooled dataset were 8 (0.80) for tildrakizumab $100 \mathrm{mg}$ and 4 (0.43) for tildrakizumab $200 \mathrm{mg}$. These serious GI AEs included abdominal pain, constipation, diverticulum, dyspepsia, gastritis, thrombosed haemorrhoids, esophageal polyp, pancreatitis (1 patient each) among tildrakizumab $100 \mathrm{mg}$ patients and abdominal hernia, upper abdominal pain, acute pancreatitis, and salivary gland enlargement (1 patient each) among tildrakizumab 200 mg patients.

Conclusions: In this post-hoc analysis of patients from 3 large randomised clinical trials, serious GI AEs were infrequent and there were no new cases of IBD or exacerbations of IBD.

\section{REFERENCES:}

[1] Papp, et al. Br J Dermatol 2016;174(6):1426

[2] Reich, et al. Lancet 2017;390(10091):276-288.

Acknowledgements: This study was funded by Merck and Co., Inc. Editoria support for abstract submission was provided by Fishawack Communications and funded by Sun Pharmaceutical Industries, Inc. Analyses were previously presented at the American Academy of Dermatology. Annual Meeting, San Diego, California, USA, 2018

Disclosure of Interest: M. Gooderham Grant/research support from: Abbvie Inc., Akros Pharma Inc., AMGEN Inc., Boehringer Ingelheim International GmbH, Bristol-Myers Squibb Company, Celgene, Dermira Inc. Eli Lilly and Company, Galderma SA GlaxoSmithKleine Janssen Inc. LEO Pharma Medlmmune Merck and Co. Novartis, Pfizer Inc., Regeneron Pharmaceuticals Inc. Roche Laboratories Sanofi Genzyme UCB Valeant Pharmaceuticals Inc., Consultant for: Akros Pharma Inc., AMGEN Inc., Boehringer Ingelheim International $\mathrm{GmbH}$, Celgene, Eli Lilly and Company, Janssen Inc. Novartis, Sanofi Genzyme, Valeant
Pharmaceuticals Inc., Speakers bureau: Abbvie Inc. Actelion Pharmaceuticals, AMGEN Inc., Boehringer Ingelheim International GmbH, Celgene, Eli Lilly and Company, Galderma SA, Janssen Inc., LEO Pharma, Novartis, Pfizer Inc. Regeneron Pharmaceuticals Inc., Sanofi Genzyme Valeant Pharmaceuticals Inc. B. Elewski Grant/research support from: Abbvie, Boehringer Ingelheim, Celgene Incyte, Lilly, Merck, Novartis, Pfizer, Regeneron, Sun Pharma, Viamet, Valeant Pharmaceuticals, Consultant for: Celgene, Lilly, Novartis, Pfizer, Sun Pharma, Valeant; all funds derived from her participation have been paid to her university, D. Pariser Grant/research support from: Abbott Laboratories, Amgen, Asana Biosciences, Bickel Biotechnology, Celgene, Dermavant Sciences, Eli Lilly, LEO Pharma US, Merck and Co., Inc., Novartis, Novo Nordisk, Ortho Dermatologics, Peplin Inc., Pfizer Inc., Photocure ASA, Promius Pharmaceuticals, Regeneron Stiefel a GSK company, and Valeant Pharmaceuticals, Consultant for: Bickel Biotechnology, Biofrontera AG, Celgene Corporation, Dermira, DUSA Pharmaceuticals, LEO Pharma US, Novartis, Promius Pharmaceuticals, Regeneron, Sanofi, TheraVida, and Valeant Pharmaceuticals, H. Sofen Grant/research support from: Amgen, Boehringer Ingelheim, Janssen, Lilly, Merck and Co., Inc. Novartis, Pfizer, Consultant for: Janssen, Lilly, Novartis, Speakers bureau: Janssen, Lilly, Novartis, A. Mendelsohn Employee of: Sun Pharmaceutical Industries, Inc., N Cichanowitz Shareholder of: Merck and Co., Inc., Employee of: Merck Sharp and Dohme Corp., a subsidiary of Merck and Co., Inc., Kenilworth, NJ, USA, Q. Li Employee of: Merck Sharp and Dohme Corp., a subsidiary of Merck and Co., Inc. Kenilworth, NJ, USA, C. La Rosa Employee of: Merck Sharp and Dohme Corp., a subsidiary of Merck and Co., Inc., Kenilworth, NJ, USA

DOI: 10.1136/annrheumdis-2018-eular.6782

\section{THU0292 DIAGNOSTIC EXPERIENCES OF PATIENTS WITH PSORIATIC ARTHRITIS: MISDIAGNOSIS IS COMMON}

${ }^{1}$ A. Ogdie, W.B. Nowell ${ }^{2}$, E. Applegate ${ }^{2}$, K. Gavigan ${ }^{2}$, S. Venkatachalam ${ }^{2}$, M. de la $\mathrm{Cruz}^{3}$, E. Flood ${ }^{3}$, E.J. Schwartz ${ }^{3}$, B. Romero ${ }^{3}$, P. Hur ${ }^{4}{ }^{1}$ Perelman School of Medicine at the University of Pennsylvania, Philadelphia; ${ }^{2}$ Global Healthy Living Foundation, Upper Nyack; ${ }^{3}$ ICON, Gaithersburg; ${ }^{4}$ Novartis Pharmaceuticals Corporation, East Hanover, USA

Background: Psoriatic arthritis (PsA) is a heterogeneous, chronic, immunemediated disease characterised by a range of musculoskeletal conditions includ ing joint pain, swelling, enthesitis and dactylitis as well as skin and nail manifestations. Early diagnosis of PsA is important as shorter time to treatment may improves outcomes. ${ }^{1}$ However, PsA is often undiagnosed or misdiagnosed. ${ }^{2}$ There is limited information on the diagnostic experiences of patients with PsA, including medical care sought and potential barriers to diagnosis.

Objectives: To determine patients' experiences related to the diagnosis of PsA including initial symptoms experienced, medical care sought, and time to diagnosis.

Methods: US patients aged $\geq 18$ years with a self-reported diagnosis of PsA were recruited through CreakyJoints (www.Creakyjoints.org), an online patient support community comprising patients with arthritis and arthritis-related diseases and their caregivers, and outreach through social media. Participants completed an online survey designed to collect data on socio-demographics, clinical symptoms, disease burden, and diagnosis history, including initial PsA symptoms experienced, types of health care providers seen, misdiagnoses received before a diagnosis of PsA, and time to PsA diagnosis. Survey questions were developed following analysis of qualitative interviews of patients with PsA and clinical experts, as well as a targeted literature review.

Results: Of the 203 patients included in the study, 172 (85\%) were female, with a mean (SD) age of $51.6(10.8)$ years; 132 patients $(65 \%)$ had private insurance, 61 $(30 \%)$ Medicare, and 25 (12\%) Medicaid. The most common initial symptoms that led patients to seek medical attention were joint pain (142 patients [70\%]), stiffness (109 [54\%]), swollen joints (101 [50\%]), skin rash/psoriasis (97 [48\%]), and fatigue (96 [47\%]). Most patients (153 [75\%]) sought medical treatment within 2 years of symptom onset. During the diagnosis process, patients most commonly sought care from a general practitioner (162 [80\%]), rheumatologist (135 [66\%]), dermatologist $(67[33 \%])$, orthopedist (44 [22\%]), and/or podiatrist (25 [12\%]) Only 8 patients $(4 \%)$ reported that they had never received a misdiagnosis; common misdiagnoses were psychosomatic disease, osteoarthritis, and anxiety/ depression (figure 1). Patients reported median (IQR) time since diagnosis of 6.0 $(2-11.5)$ years. Many patients (94 [51\%]) received a diagnosis of PsA $\leq 1$ year after seeking medical attention; however, $25(17 \%)$ and $31(15 \%)$ patients received a PsA diagnosis $>5$ and $>10$ years after seeking medical attention for the first time, respectively. 


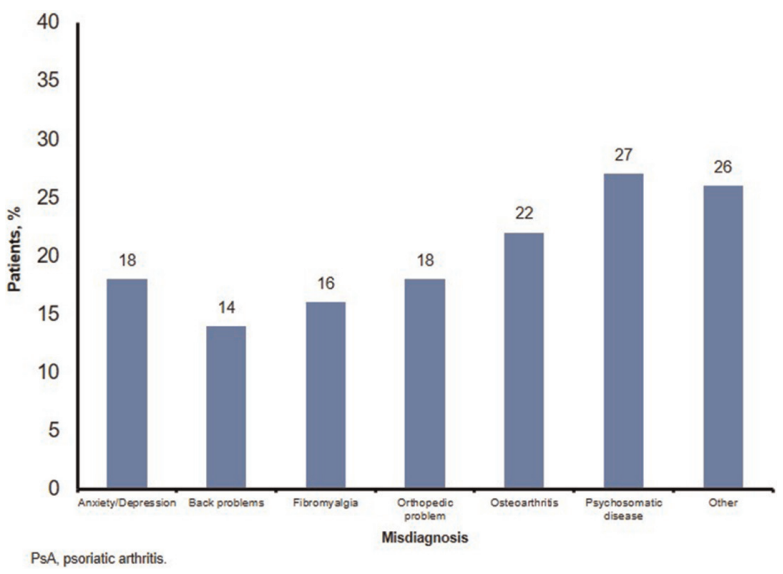

Abstract THU0292 - Figure 1. Misdiagnoses Received Before Diagnosis of PsA ( $N=203$ ). PsA, psoriatic arthritis

Conclusions: This study showed that patients often had substantial delays and misdiagnoses before they received a PsA diagnosis. Increased understanding of the diagnostic barriers may lead to earlier diagnosis and appropriate treatment that may improve outcomes.

REFERENCES:

[1] Haroon M, et al. Ann Rheum Dis 2015;74(6):1045-1050.

[2] Mease P, Armstrong A. Drugs 2014;74(4):423-441.

Acknowledgements: This study was sponsored by Novartis Pharmaceuticals Corporation, East Hanover, NJ.

Disclosure of Interest: A. Ogdie Grant/research support from: Pfizer and Novartis, Consultant for: Abbvie, BMS, Eli Lilly and Company, Novartis, Takeda, and Pfizer, W. B. Nowell Employee of: Global Healthy Living Foundation, E. Applegate: None declared, K. Gavigan Employee of: Global Healthy Living Foundation, S. Venkatachalam Employee of: Global Healthy Living Foundation, M. de la Cruz Employee of: ICON, E. Flood Employee of: ICON, E. Schwartz Employee of: ICON, B. Romero Employee of: ICON, P. Hur Employee of: Novartis Pharmaceuticals Corporation

DOI: 10.1136/annrheumdis-2018-eular.4374

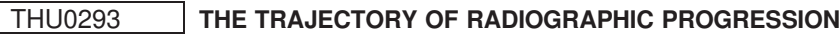 SLOWS AMONGST PATIENTS WITH PSORIATIC ARTHRITIS TREATED WITH ANTI-TNF}

${ }^{1}$ A. Allard, A. Antony ${ }^{1}$, G. Shaddick ${ }^{2}$, D. Jadon ${ }^{3}$, C. Cavill ${ }^{1,4}$, E. Korendowych ${ }^{1}$, N. McHugh ${ }^{1,4}$, W. Tillett ${ }^{1,4}$. ${ }^{1}$ Rheumatology, Royal National Hospital for Rheumatic Diseases, Bath; ${ }^{2}$ Mathematical Sciences, University of Exeter, Exeter,

${ }^{3}$ Rheumatology, Cambridge University Hospitals, Cambridge; ${ }^{4}$ Pharmacy and Pharmacology, University of Bath, Bath, UK

Background: Radiographic damage is an important outcome in psoriatic arthritis (PsA) but the natural history of radiographic progression has not been well described. Randomised Controlled Trials (RCTs) of treatment with anti-TNF have shown reduced damage progression in the short term but long term real world data is lacking.

Objectives: We set out to describe the long term radiographic progression amongst patients with PsA who transitioned from conventional synthetic Disease Modifying Drugs (csDMARDs) to anti-Tumour Necrosis Factor alpha inhibitors (anti-TNF) in routine care.

Methods: A retrospective sample of 28 patients (CASPAR criteria for PsA) was taken from the Bath longitudinal cohort. All patients had radiographs of the hands and feet taken at approximately 3 time points; 5 years before $\left[\mathrm{T}_{0}\right]$, at the time of $\left[\mathrm{T}_{1}\right]$ and 5 years post $\left[\mathrm{T}_{2}\right]$ commencing anti-TNF treatment. 84 radiographs were scored using the Sharp-van der Heijde modified method (VDH) and osteoproliferation was scored using the psoriatic arthritis Ratingen score (PARS) method, by three assessors (AA, AA and WT). The assessors were blinded to the patient details and the order of the $\mathrm{x}$-rays. Inter- and intra-rater reliability was assessed using intra-class correlation coefficients (ICC). Cumulative probability plots were used to describe radiographic progression on csDMARDs ( $T_{0}$ to $T_{1}$ ) compared with subsequent anti-TNF treatment $\left(T_{1}\right.$ to $\left.T_{2}\right)$. Change between probability plots was determined using the two-sample Kolmogorov-Smirnov test (K-S test). This sample size was calculated to ensure $90 \%$ power to determine the smallest detectable difference of the VDH (6.25) to $5 \%$ significance level.
Results: Of the 28 patients 15 were male, the mean age was 61 years (SD 13.4) and mean disease duration at $T_{0}$ was 11.2 years (SD 11.14). The mean study follow up period was 10.2 years (SD 2.76). Inter- and intra-rater reliability was $>0.9$ The median VDH score at baseline was 8.5 (IQR 1.75-27.5). The median scores for erosions, joint space narrowing and proliferation at baseline were 1.5 (IQR 08.5), 4.5 (IQR 1-15) and 7 (SD1-13.5) respectively.

The median change in VDH score on csDMARDs was 11.00 (IQR 3-19.5) and on anti-TNF was 4.00 (IQR 0.75-11.5). The median rate of change in VDH score per year was 2.29 (IQR 0.95-3.81) on csDMARDs and on anti-TNF was 1.04 (IQR 0.16 ) $p=0.012$ (figure 1). These scores correlate with observed improvements in clinical disease outcome measures including tender joint count, swollen joint count and nail score (data not shown).

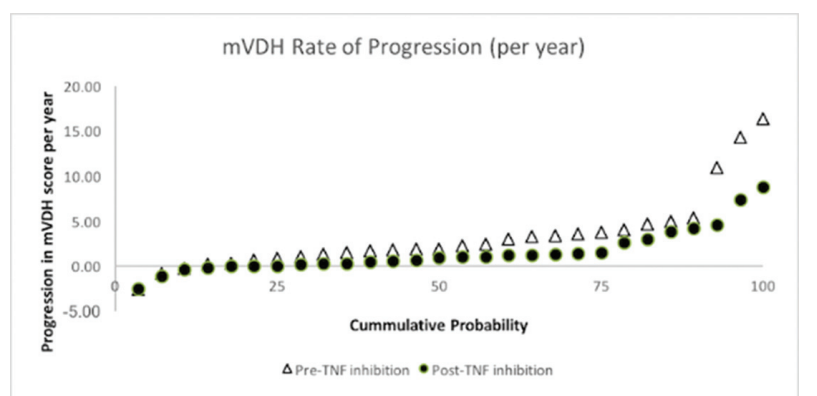

Abstract THU0293 - Figure 1. mVDH rate of progression (per year). $\Delta$ pre-TNF inhibition -post-TNF inhibition

Conclusions: In this real world observational cohort study the rate of radiographic progression slows following commencement of anti-TNF therapy. The overall rate of damage progression was low over long term follow up of more than ten years even amongst this group of more severe patients selected on the basis they progressed to anti-TNF therapy.

Disclosure of Interest: None declared

DOI: 10.1136/annrheumdis-2018-eular.3154

\section{THU0294 5-YEAR EFFICACY AND SAFETY OF APREMILAST TREATMENT IN SUBJECTS WITH PSORIATIC ARTHRITIS: POOLED ANALYSIS OF THE PALACE STUDIES}

${ }^{1}$ A. Kavanaugh, D.D. Gladman ${ }^{2}$, C.J. Edwards ${ }^{3}$, G. Schett ${ }^{4}$, B. Guerette ${ }^{5}$, N. Delev ${ }^{5}$, L. Teng ${ }^{5}$, M. Paris ${ }^{5}$, P.J. Mease ${ }^{6} .{ }^{1}$ University of California, San Diego, School of Medicine, La Jolla, USA; ${ }^{2}$ Krembil Research Institute, Toronto Western Hospital, Toronto, Canada; ${ }^{3}$ University of Southampton, Southampton, UK; ${ }^{4}$ Friedrich-Alexander-Universität Erlangen, Nürnberg und Universitätsklinikum Erlangen, Erlangen, Germany, ${ }^{5}$ Celgene Corporation, Summit, ${ }^{6}$ Swedish Medical Center and University of Washington School of Medicine, Seattle, USA

Background: Apremilast (APR) is an oral phosphodiesterase 4 inhibitor for the treatment of adult patients with active psoriatic arthritis (PsA)

Objectives: The long-term efficacy and safety of APR treatment were evaluated for up to 5 years in subjects with active PsA from the phase 3 PALACE 1, 2, and 3 studies.

Methods: Subjects were randomised at baseline $(B L)(1: 1: 1)$ to receive placebo (PBO), APR $30 \mathrm{mg}$ BID (APR30), or APR $20 \mathrm{mg}$ BID (APR20). PBO subjects were re-randomised (1:1) to APR30 or APR20 at Week 16 (early escape) or Week 24. Double-blind APR treatment continued to Week 52; subjects could continue APR during an open-label, long-term treatment phase for up to 5 years. Safety was assessed at each visit throughout the study.

Results: A total of 1493 subjects were randomised and received $>1$ dose of study medication (PBO: $n=495$; APR30: $n=497$; APR20: $n=501$ ). Of those randomised to APR30 at BL, 66.6\% (331/497) completed 260 weeks of treatment. A Week 52, modified ACR20, ACR50, and ACR70 responses were achieved by $55.3 \%, 26.1 \%$, and $11.9 \%$ of APR30 subjects, respectively, regardless of when APR was started (BL, Week 16, or Week 24). Sustained response rates were observed with continued APR30 treatment at Week 260 (table 1). Marked SJC improvements were seen, with mean percent reduction of $82.3 \%$ at Week 260 ; TJC reduction was $72.7 \%$. At Week $260,62.4 \%$ (136/218) of APR30 subjects with BL enthesitis achieved a MASES of $0 ; 80.9 \%(114 / 141)$ with BL dactylitis achieved a dactylitis count of 0 . A total of $52.6 \%$ of APR30 subjects achieved $\mathrm{HAQ}$-DI MCID $\geq 0.35$ at Week 260 , and low disease activity and remission, as defined by the cDAPSA (score $\leq 13$ ), were achieved by $60.4 \%$ of APR30 subjects. Sustained responses in psoriatic skin involvement were observed with continued treatment at Week 260 in APR30 subjects who had $\geq 3 \%$ BL psoriasis body 